\title{
Consumo de la leche de llama (Lama glama) en los Andes Peruanos
}

\section{Consumption of the llama (Lama glama) milk in Peruvian Andes}

\author{
Manuel Jaime Dávila Acevedo* \\ http://dx.doi.org/10.21503/CienciayDesarrollo.2007.v8.01
}

\section{RESUMEN}

Se desconoce de forma fehaciente si en Sudamérica se consume o consumió leche de llama (Lama glama). Precisamente la respuesta a esta interrogante ha motivado el presente trabajo de investigación. La llama, principalmente por su tamaño y las múltiples formas de utilización que tuvo por parte del antiguo poblador sudamericano (carga, fibra, carne, etc.), sería una probable "productora de leche" para el consumo humano, por poseer su leche características químicas y organolépticas que la hacen apta. Basándonos principalmente en libros y artículos de cronistas, historiadores y estudiosos de los camélidos sudamericanos, encontramos razones que afirman o rechazan el consumo de esta leche. Al respecto, tienen mayor sustento aquellas teorías que rechazan su sustento en el Antiguo Perú, básicamente por la no necesidad de utilizarla, ya que los pobladores tenían cubiertos sus requerimientos nutricionales. Además, existen consideraciones basadas en parámetros culturales de respeto a las especies. Todo ello permitiría llegar a la conclusión de que efectivamente la leche no fue consumida. Sin embargo, no se descarta la posibilidad de un consumo actual de leche de llama, aunque de manera restringida, y más bien ligado a la supervivencia. La perspectiva de este estudio abre la posibilidad futura de una selección y mejoramiento de las llamas para convertirlas en animales lecheros.

Palabras clave: llama (Lama glama), leche, alimentación, cosmovisión, consumo, andino, Sudamérica.

\section{ABSTRACT}

As of today, in realistic terms, it is unknown whether in South America llama's (Lama glama) milk was or is consumed. The present study tries to find an answer to this interrogation, mainly by the size and manifold uses given to the llama by ancient South Americans (loading, fiber, meat, etc.), could probably be a milk producer for human consumption, having the chemical and organoleptic characteristic that makes it apt. Based mainly on books and articles of chroniclers, historians and investigators of South America camelides we found reasons that confirm or reject the consumption of this type of milk, having a greater sustenance those that reject its use in old Peru, basically because the nutritional needs of the Peruvian population was reasonable fulfilled with other foods. Those who reject this theory based on cultural parameters, reach to the conclusion that llama milk was indeed not consumed. In spite of above mentioned conclusion we do not discard the possibility of llama's milk consumption in a restricted way, but related to survival needs, in addition to the future possibility of a selection and improvement of llamas to turn them into milk animals.

Key words: llama (Lama glama), milk, feeding, cosmovision, consumption, Andean, South America.

\footnotetext{
* Licenciado por la Facultad de Medicina Veterinaria de la Universidad Alas Peruanas.
} 


\section{INTRODUCCIÓN}

Las llamas son animales oriundos del Perú, Bolivia, Chile y Argentina ${ }^{1}$. En el Perú, la población de llamas llega a cerca de un millón de cabezas $^{1,2,3}$. En la época prehispánica, fue introducida en Ecuador y Colombia, y a partir del siglo XIX, a otros países. Actualmente existen poblaciones de llamas en USA, Canadá, Nueva Zelanda, Australia, Francia, Italia y otros países ${ }^{1}$, llegando su población aproximada a 3,7 millones de cabezas en Sudamérica y aproximadamente $100000 \mathrm{ca}$ bezas repartidas a nivel mundial ${ }^{1,2,3}$. Se calcula que durante el Incanato la población de llamas llegaba a los 12 millones de cabeza ${ }^{4}$, cálculo que se hace considerando que luego de la conquista de América, la población de camélidos se redujo en $3 / 4$ partes debido a una epidemia de sarna, y tomando en cuenta también que esta población no ha variado considerablemente en el transcurso de los siglos posteriores.

La vida de esta especie animal en Sudamérica está estrechamente ligada al desarrollo del hombre nativo de estas tierras, el que luego de cazarlas pasó a domesticarlas y criarlas hasta lograr un sistema de manejo propio y dándole múltiples usos.

Se sabe que al llegar los españoles al Perú (1535), estos se encontraron con inmensos rebaños de llamas que eran utilizados por los indios, y a los que ellos llamaron "ovejas de la tierra" ${ }^{5,6}$.

Las llamas se encontraban en todos los pisos ecológicos, a excepción de la selva, pero fueron desplazadas a las alturas por la presión de su cacería y el uso de ellas como bestias de carga, sometiéndolas a un excesivo trabajo en las minas durante la época colonial. Además, fueron desplazadas también por la introducción de especies foráneas, como equinos, bovinos, ovinos y caprinos. Debido a esto, con el tiempo se fue perdiendo el hábito y las técnicas de crianza de estos animales, no conociéndose actualmente en forma clara y precisa los usos y las técnicas aplicadas en su manejo ${ }^{7,8,9}$.

La pérdida de información y de hábitos de crianza puede haber llevado a la pérdida de variabilidad genética de la llama, ya que, por ejemplo, antes se hablaba de una raza de llamas gigantes (de 1,6 a 1,7 m da altura a la cruz), de las cuales ya no se encuentran ejemplares.

Por otra parte, se desconoce si los pobladores sudamericanos antiguos tenían acceso o usaban alguna fuente de productos lácteos. Al observarse las especies que se encuentran en el continente, se pede presumir, principalmente por su tamaño, que la única para tal fin era la llama, teniendo en cuenta que la leche del camello bactriano asiático, pariente de la llama, es consumida ${ }^{6}$.

Por tales razones, se busca determinar si el poblador sudamericano consume o consumió leche de llama para satisfacer determinadas necesidades, es decir, como alimento, medicina, hechicería, etc.

La investigación histórica busca determinar el consumo de leche de llama desde la domesticación de estas, pasando por las culturas preíncas e inca y llegando hasta la actualidad. Busca también aportar al conocimiento humano, considerando a la leche de llama como posible recurso alimenticio de los pobladores altoandinos, además de promover la selección y mejoramiento genético de las llamas como productoras lecheras. Sin duda, tales aportes mejorarán además la autovaloración de los criadores de llamas, generando en ellos la convicción de que son poseedores de animales de alto valor económico, social e histórico, a más de realzar su noble labor, digna de transmitirse a las futuras generaciones.

\section{Orígenes}

El centro de evolución de la familia de los 
camélidos fue Norteamérica, hace unos $50 \mathrm{mi}$ llones de años, según lo indican las huellas fósiles encontradas. Sus antepasados dieron lugar al Poebrotherium, que era del tamaño de una oveja y proliferaba alrededor de 30 millones de años a. C, en el territorio que hoy ocupan los Estados Unidos de Norteamérica ${ }^{15}$. En el mioceno, conforme se produjo el calentamiento del planeta, ocasionando climas áridos y la expansión de las praderas, los camélidos aumentaron de tamaño, se adaptaron a un alimento de calidad secundaria y desarrollaron un hábito de pastoreo itinerante, adecuado a la migración a través de las estepas en expansión?

Hace unos 5 millones de años había rebaños de camélidos avanzando hacia América del Sur, cuando en el período del mioceno apareció el puente de tierra entre América del Norte y esta, evolucionando hasta originar a los camélidos sudamericanos actuales, así como otros ya extintos (Lama gracilis) $)^{7}$.

Otros grupos de camélidos primitivos pasaron de Norteamérica a Asia por el Estrecho de Bering, dando lugar a los camélidos asiáticos (camello bactriano y dromedario), que se encuentran principalmente en Asia Central y las regiones del África comprendidas entre el Mediterráneo y Senegal, y el Océano Atlántico y el Índico, respectivamente ${ }^{6}$.

Finalmente, los camélidos desaparecieron de América del Norte, ya que fueron cazados hasta la extinción. En las praderas norteamericanas se hallaron restos de especies únicas, como los camelops y los paleoglama ${ }^{8}$. Sin embargo, en Asia y Sudamérica, los camélidos fueron domesticados hace 4000 ó 5000 años $^{3,15}$.

\section{Distribución y hábitat}

La llama se distribuye actualmente en el sur del Perú, en el oeste de Bolivia, en la puna de Atacama, en Chile, y en el noroeste de Argentina.
Habitan entre los 3600 y los 5500 m.s.n.m., cubriendo una extensión de mas de $2000 \mathrm{~km}$ en la Cordillera de los Andes.

En Sudamérica existe una cantidad aproximada de 3,7 millones de llamas, encontrándose el $70 \%$ de estas en Bolivia, el $25 \%$ en el Perú ${ }^{23,16}$ y el $5 \%$ restante entre Argentina y Chile.

En el Perú, la región ecológica que actualmente ocupan los camélidos es la puna, siendo este el territorio más amplio de la región andina (35\% de la sierra). Económicamente, constituye la segunda fuente de recursos naturales dentro de los grupos de pastores y de agricultores ${ }^{7}$.

\section{Alimentación}

Las llamas se alimentan casi exclusivamente de hierbas perennes, especialmente cortas, típicas de estepas de altura, y también de vegetarles como la Distichia, de brotes siempre verdes ${ }^{7}$.

En su mayor parte, las llamas se alimentan de gramíneas de los géneros Festuca, Poa, Bromus, Calamgrostis y Stipa sp. De todas ellas, las festucas y los calamagrostis se desarrollan mejor en los suelos húmedos, y constituyen la dieta preferida de los camélidos ${ }^{7,8,18}$. Sin embargo, durante las faenas como bestias de carga consumen cualquier vegetación ${ }^{8}$.

\section{Reproducción}

Su período de gestación dura $348 \pm 9$ días. Las hembras alcanzan la madurez sexual al año de edad, pero mediante un correcto manejo, estas son servidas recién entre los 2 y 3 años de edad. Generalmente, el macho se utiliza para la procreación a partir de los 3 años de edad ${ }^{21}$. Las llamas hembras presentan ovulación inducida, siendo este evento desencadenado por la cópula $^{22}$.

La época de apareamiento y parición va des- 
de enero hasta abril, y después de un mes de la parición, la hembra queda expedita para ser fecundada. Estas características reproductivas son relativamente comunes para todos los camélidos andinos. La hembra pare una sola cría, aunque en raras ocasiones puede tener dos crías en una sola parición $^{21}$.

Los camélidos tienen un útero con dos cuernos, y, curiosamente, el mayor porcentaje de las gestaciones se produce en el cuerno uterino izquierdo ${ }^{18}$. La placenta es del tipo difuso y es eliminada 2 ó 3 horas después del parto. La cría nace bien desarrollada, y a las 2 ó 3 horas del parto ya es capaz de ingerir calostro y seguir a su madre.

Consumo, características y composición de la leche de llama

El consumo de la leche de llama es un tema controversial, pues existen al respecto opiniones diametralmente opuestas. Actualmente, en el mundo se conoce de la utilización de la leche del camello bactriano, que es criado en $\mathrm{Asia}^{6}$, por lo que se puede presumir que la llama, que también es un camélido, pudo ser usada por los antiguos sudamericano como animal no solo de carga y como proveedora de lana y carne, sino que también puso ser productora de leche para el consumo humanos.
Los camélidos asiáticos (dromedarios) constituyen una importante fuente de leche para los pobladores de las comunidades rurales, donde los ordeñan 3 veces al día para producir alrededor de nueve litros de leche diarios en la temporada húmeda y 6 litros de leche diarios de leche durante la época seca, momento en el que esta leche es particularmente apreciada, ya que escasea la del resto del ganado ${ }^{15}$.

Es importante saber que la evaluación de la composición de la leche de camélidos indica que posee valor nutritivo para los humanos ${ }^{19}$. (Ver Tabla 1.)

\section{Caracteristicas quimicas}

Un estudio detallado en los Estados Unidos de América demostró que la leche de llama tiene un contenido más alto de azúcar $(5,61 \%)$ y una proporción más baja de grasas que la leche de otros rumiantes domésticos ${ }^{26}$.

La leche de llama contiene más calcio y menos sodio, potasio y cloruro, pero la concentración de minerales es similar a la encontrada en la leche de vacunos. La composición de la leche puede variar según la localización geográfica, y también probablemente debido a las diferencias

Tabla 1. Composición porcentual de la leche de diferentes especies animales

\begin{tabular}{|c|c|c|c|c|c|c|c|c|c|c|c|c|}
\hline TIPOS & Grasa & & Azúcar & & Caseína & & Albúmina & & Ceniza & & SÓLIDOS & AGUA \\
\hline Humano & 3,74 & + & 6,37 & + & 0,80 & + & 1,21 & + & 0,30 & $\rightarrow$ & 12,42 & 87,58 \\
\hline Vaca & 3,68 & + & 4,94 & + & 2,88 & + & 0,51 & + & 0,72 & $\rightarrow$ & 12,73 & 87,27 \\
\hline Cabra & 4,07 & + & 4,64 & + & 2,87 & + & 0,89 & + & 0,85 & $\rightarrow$ & 13,32 & 86,68 \\
\hline Oveja & 7,90 & + & 4,17 & + & 4,17 & + & 0,98 & + & 0,93 & $\rightarrow$ & 18,15 & 80,71 \\
\hline Búfalo & 7,51 & + & 4,77 & + & 4,26 & + & 0,46 & + & 0,84 & $\rightarrow$ & 17,84 & 82,16 \\
\hline Camello & 5,38 & + & 5,39 & + & 3,49 & + & 0,38 & + & 0,74 & $\rightarrow$ & 15,38 & 87,13 \\
\hline Llama & 3,15 & + & 5,60 & + & 3,00 & + & 0,90 & + & 0,80 & $\rightarrow$ & 13,45 & 86,55 \\
\hline Asno & 2,53 & + & 6,19 & + & 0,79 & + & 1,06 & + & 0,47 & $\rightarrow$ & 11,04 & 89,03 \\
\hline Yegua & 1,14 & + & 5,87 & + & 1,30 & + & 0,75 & + & 0,36 & $\rightarrow$ & 9,42 & 90,58 \\
\hline Reno & 22,46 & + & 2,81 & + & 8,38 & + & 3,02 & + & 0,91 & 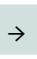 & 37,58 & 63,30 \\
\hline Perro & 9,26 & + & 3,11 & + & 4,15 & + & 5,57 & + & 1,49 & $\rightarrow$ & 23,58 & 77,00 \\
\hline
\end{tabular}


en la dieta y al manejo. Sin embargo, la composición de la leche no se ve afectada por la etapa de la lactancia, el número de lactancia o la condición corporal ${ }^{20}$.

En estudios realizados en el Perú, se determinaron algunos valores en la composición de la leche de llama. Medina y Buztinza (1985) obtuvieron la siguiente composición química: extracto $3,15 \%$, materia grasa $3,15 \%$, caseína 3,0 \%, albúmina $0,9 \%$, lactosa $5,6 \%$, y materia mineral 0,8 $\%{ }^{18}$. A su vez, Ruiz de Castilla y Escobar (1993) obtuvieron la composición y características físicoquímicas del calostro y leche de llama, con los siguientes valores:

\begin{tabular}{|lrr}
$\begin{array}{c}\text { Componente } \\
\text { o característica }\end{array}$ & Calostro & Leche \\
\hline Densidad & 1,0762 & 1,0348 \\
\hline Grasa & $5,37 \%$ & $4,26 \%$ \\
\hline Caseína & $15,75 \%$ & $6,12 \%$ \\
\hline Lactosa & $2,61 \%$ & $4,75 \%$ \\
\hline Sólidos no grasos & $14,03 \%$ & $8,4 \%$ \\
\hline Sólidos totales & $17,06 \%$ & $10,38 \%$ \\
\hline Ceniza & $1,02 \%$ & $0,78 \%$ \\
\hline
\end{tabular}

Comparando los valores promedio de la leche de llama (ver Tabla 2) con la de vaca, cabra, oveja y humano, podemos señalar que la leche está formada por lóbulos de grasa que en el caso de la llama corresponden al 3, $37 \%$, la grasa de la leche de vaca se encuentra en 3,68 \%, la de cabra en $4,1 \%$, la de oveja en 7,9\% y la de humano en 4,2\% (ver Figura 1). Estos glóbulos se hallan suspendidos en una solución que contiene el

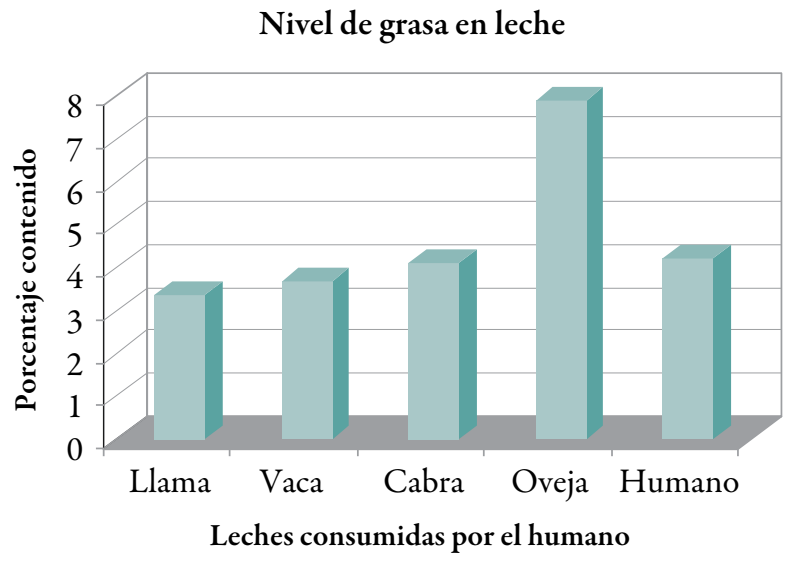

Figura 1. Comparación del nivel de grasa contenido en leches de consumo humano

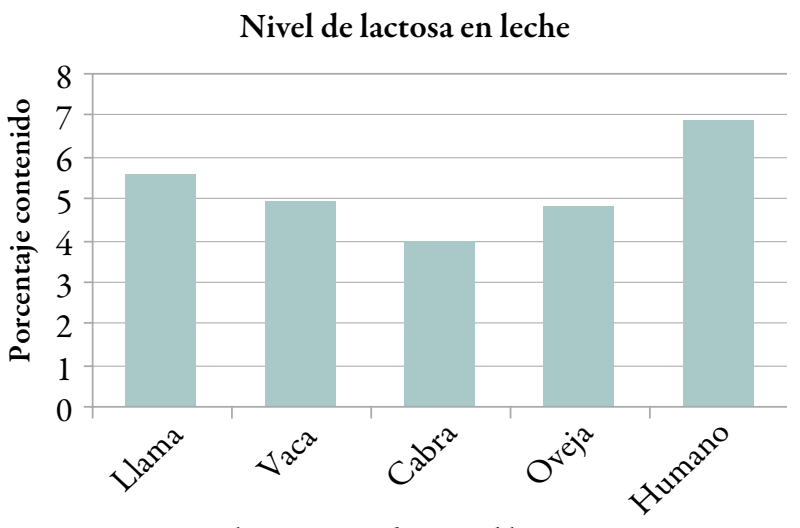

Leches consumidas por el humano

Figura 2. Comparación del nivel de lactosa contenido en leches de consumo humano

azúcar de la leche (lactosa). En el caso de la llama, el porcentaje de lactosa es de 4, $94 \%$, en las cabras está en $4 \%$, en las ovejas en $4,8 \%$, y en los humanos en 6,9\% (ver Figura 2). Las proteínas se encuentran en la leche de llama en 3,9\%, en

Tabla 2. Composición química promedio de leches de consumo humano

\begin{tabular}{lrrrrc}
\multicolumn{1}{c}{ Tipos } & Grasa & Lactosa & Agua & Proteínas & $\begin{array}{c}\text { mg de calcio en } \\
\mathbf{1 0 0 m l}\end{array}$ \\
\hline Llama & 3,37 & 5,61 & 86,55 & 3,9 & 133 \\
Vaca & 3,68 & 4,94 & 87,27 & 3,39 & 125 \\
Cabra & 4,1 & 4 & 87 & 3,3 & 130 \\
Oveja & 7,9 & 4,8 & 80,7 & 5,8 & \\
Humano & 4,2 & 6,9 & 87,5 & 1 & 29 \\
\hline
\end{tabular}




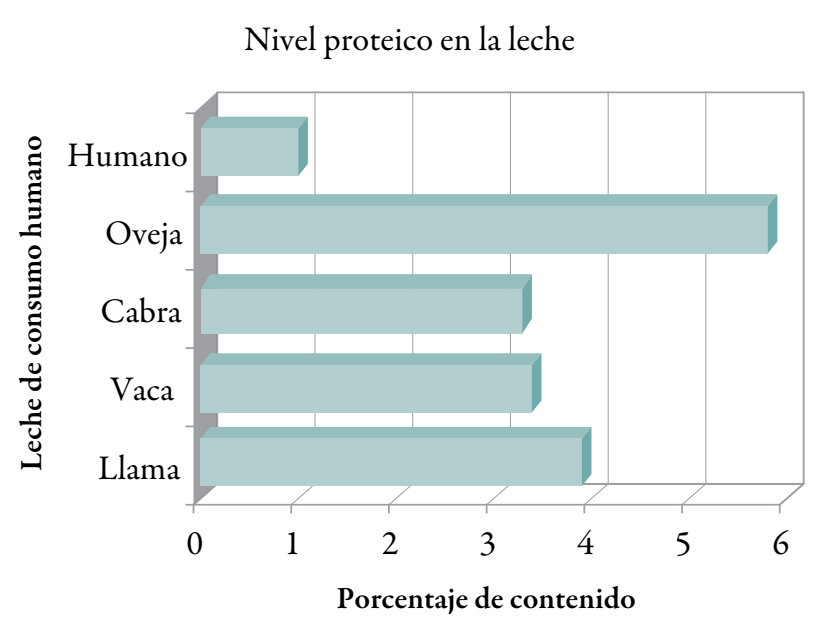

Figura 3. Comparación del nivel proteico en leches de consumo humano

la de vaca en $3,39 \%$, en la de cabra en $3,3 \%$, en la de oveja en 5,8\%, y en la humana en $1 \%$ (ver Figura 3). El calcio se encuentra en la leche de llama en una cantidad de $133 \mathrm{mg}$ por $100 \mathrm{ml}$ de leche, mientras en la leche de vaca se encuentran en $125 \mathrm{mg}$ por $100 \mathrm{ml}$ de leche, en la leche de cabra en $130 \mathrm{mg}$ por $100 \mathrm{ml}$, y en la humana en $29 \mathrm{mg}$ por $100 \mathrm{ml}$ (ver Figura 4). Todas las leches son deficientes en hierro, y son inadecuadas como fuente de vitamina $\mathrm{C}^{27}$.

La leche de llama está compuesta por un $86,55 \%$ de agua, la leche de vaca por un 87,27 $\%$, la de cabra por un $87 \%$, la de oveja por un $80,7 \%$, y la humana por un $87,5 \%{ }^{27}$.

Leyva V. (1988) determinó la cantidad de leche que produce la llama, además de su calidad, a cuyo respecto afirma: "Algunas llamas dan 3 y hasta 4 litros por día. En general, se podría ordeñar medio litro diario sin perjudicar a la cría" ${ }^{18}$.

Flores Ochoa (1968) hace mención de la producción de leche de llama indicando que una llama recién parida da $1 / 2$ litro de leche, ordeñándola cada 12 horas $^{28}$.

\section{Caracteristicas organolépticas}

El sabor de la leche de llama es dulce, con mg de calcio contenido en $100 \mathrm{ml}$ de leche

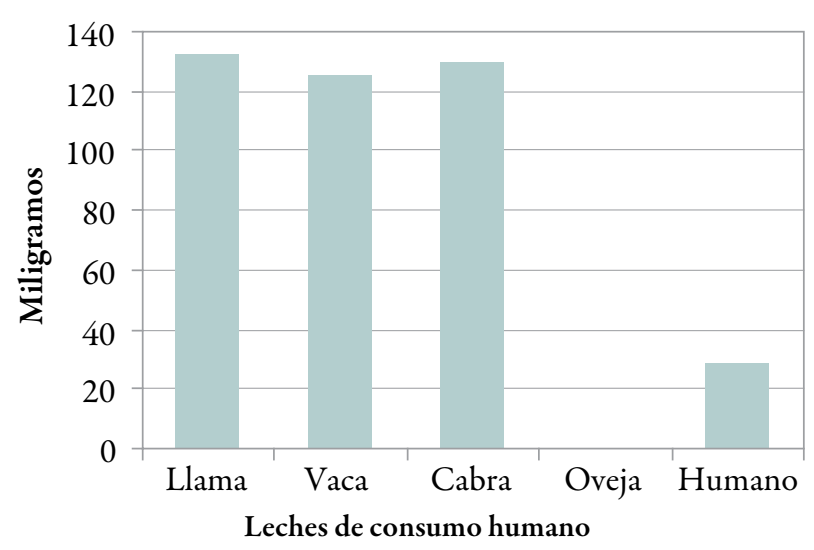

Figura 4. Comparación del nivel de calcio contenido en leches de consumo humano

un color blanco, y el sabor del calostro tiende a ser ligeramente salado, con un color amarillo nácar ${ }^{18,31}$. Otros autores afirman que la leche de llama posee mal sabor ${ }^{29}$.

\section{Teorías sobre el consumo de la leche de llama}

\section{Teorias a favor del consumo}

Fray Vicente Valverde, quien fuera el primer sacerdote en pisar tierras incaicas, en 1533, junto a Francisco Pizarro, y el que se entrevistó con Atahualpa y fuera primer obispo del Cusco en 1539, al describir esta ciudad escribió: “...lana de ovejas de acá, queso y leche vendiéndolo”2. Recordemos que llamaba "ovejas de acá" a los camélidos sudamericanos.

Palermo (1986), al tratar el tema de los camélidos en Chile, cita a Gonzales de Nájera durante su permanencia en Chile (1601 -1607), quien escribió que los indígenas consumían su leche ${ }^{2}$.

El naturalista inglés Henry Walter Bates (1825 -1892) afirmaba que los antiguos peruanos utilizaron la leche de llama como alimento en forma de queso ${ }^{2}$. Referencia parecida proporciona Troll (1958), cuando indica que F. Klute califica a la llama como animal lechero ${ }^{2}$. A su vez, Álvarez (1987), al comentar los “carneros” que 
describe fray Diego de Ocaña durante su viaje por toda América Hispana entre 1599 y 1605 , anota que "también se aprovecha su carne y leche..."

Por su parte, el geógrafo peruano Emilio Romero sostiene que la llama ha colaborado con el hombre proporcionándole leche ${ }^{2}$.

Sobre la leche de camélidos, Ramón Solís (2000) afirma: "La producción de leche de alpaca y llama se basa en la capacidad de las hembras para producir leche, que posee un elevado tenor nutritivo para el hombre. Entonces ha criado y seleccionado animales, durante siglos, que son capaces de producir leche en cantidades que superan las necesidades para la alimentación de sus crías, y el excedente ha sido destinado para la alimentación humana"18.

En su libro Llama Production and Llama Nutrition in the Ecuador Highlands, Ordóñez (1994) afirma que en algunas partes de Sudamérica a las llamas también se las separa para ser ordeñadas ${ }^{31}$. A su vez, Eliseo Fernández Ruelas (1987), de la Universidad Nacional del Altiplano, dice que "las llamas madres producen leche de excelente calidad que contribuye a la alimentación humana, aunque en forma restringida"32.

Manuel Moro, del laboratorio de bacteriología de la UNMSM en los años 50, afirma lo siguiente: "si bien no creemos que la leche de alpaca llegue a sustituir en la sierra a la leche de vaca, es interesante tener presente que la alpaca, así como la vaca, posee una ubre con cuatro cuartos, y que hay alpacas que dan un volumen de leche superior al de muchas vacas de la sierra, la que en igualdad de volumen es energéticamente superior a la de vaca, y por lo tanto podría emplearse ya sea pura o mezclada con leche de vaca para la preparación de quesos, en forma similar a como se emplea la leche de oveja en ciertos lugares del sur del país, como por ejemplo la localidad de $\mathrm{Pa}$ ria (Puno)"33.
El Dr. Víctor Leyva nos narró que a raíz de un estudio sobre curva de lactación realizada en la estación del IVITA en La Raya (Cusco), se encontró que la leche obtenida fue entregada a un colegio cercano para la alimentación de los niños de la zona, no presentándose problemas de ninguna índole ante su consumo ${ }^{34}$.

Jairo Mora-Delgado y Vilma A. Holguín (2002) indican, en el boletín Ganadería en Sistemas de Producción Campesinos en América Latina, que "otra especie importante en Sudamérica desde tiempos prehispánicos son los denominados camélidos sudamericanos, ya que constituyen fuente de carne, leche, piel y fuerza de trabajo" 35 .

\section{Teorias que rechazan el consumo}

Entre los diferentes autores que niegan el consumo de la leche de llama citaremos a los siguientes

Duccio Bonavia (1966) en su obra Los camélidos sudamericanos, citando a Gade (1977), señala que las afirmaciones de Henry Bates, Troll (1958), Álvarez (1987), Emilio Romero y fray Vicente Valverde (1533), arriba citados, son erróneas, pues asevera que la leche de los camélidos ni ha sido ni es utilizada ${ }^{2}$.

Palermo (1986), sobre la afirmación de Gonzales de Nájera , agrega: “...aunque en general se sostiene que estos animales no pueden ordeñar$\mathrm{se}^{\mathrm{N}}$, dando a notar su desacuerdo con el posible consumo de la leche de llama.

Santiago E. Antúnez de Mayolo (1981) afirma: "Se podrá pensar que los pobladores del incanato eran unos tontos al no utilizar la leche de las llamas, que proporcionan un litro de leche al día. Pero si no lo hicieron, debió ser por la alta concentración de grasas y minerales que tiene la

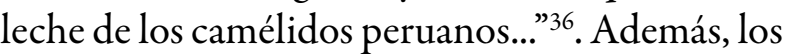


niveles de producción láctea de la llama son bajos para un posible consumo humano ${ }^{29}$. El mismo autor afirma, en referencia a las alpacas: "No hemos encontrado evidencias de que fuera emplea$\mathrm{da}$ su leche en épocas prehispánicas, probablemente por su alto contenido de grasa, que oscila entre $2 \%$ y $7 \%$, con un promedio de $4 \%$, que es muy alto para su ingestión por bebés, además de su elevado tenor proteico de 5,6\%”. Añade que las alpacas proporcionan entre 700 y 1200 c. c. de leche al día ${ }^{29}$.

Horkheiner (1973) afirma que "los antiguos peruanos, como los demás pueblos precolombinos de alta altura, no conocieron ni el huevo ni la leche, ni subproductos de esta (mantequilla, queso) como medios de alimentación. En este caso, no se puede invocar como argumento la carencia de animales apropiados, toda vez que existían aves de corra y también muchas aves silvestres. $\mathrm{Y}$ en lo tocante a los camélidos, es posible que hayan ofrecido dificultades para el ordeño, pero no se comprende por qué en el transcurso de varios miles de años de desarrollo no pudieron ser transformados en animales de ordeño tal como muchas variantes del antiguo continente" ${ }^{37}$.

Cabieses (1990) nos dice al respecto: "es importante recordar que la ausencia de leche y huevos no interfirió con el buen estado nutricional. El niño lactaba hasta los 2 años, y de allí se alimentaba igual que un adulto" 38 .

Por otro lado, los camélidos no son grandes productores de leche, lo que debe agregarse al hecho de que los niños del Antiguo Perú no eran alimentados con "leche de bestias", por razones más ligadas a la superstición y a la magia que a motivos utilitarios ${ }^{38}$.

Antúnez de Mayolo (1981) se refiere también a la idiosincrasia de la antigua mujer andina criadora de camélidos sudamericanos: "Es también una fuerte razón para presumir el no consumo de la leche de llama, basándose en que ella consideraba un deshonor y mutilación de sus capacidades como madre lactante, al permitir que su progenie se alimentase de la leche de otro ser que no fuese ella". Pero este concepto no era el único dentro de la cosmovisión andina antigua, que se basa en el respeto a todas las criaturas de la tierra, por lo que los pobladores altoandinos creían que al utilizar la leche de llama y otras especies, estaban privando a las crías de estas de una buena provisión de alimento durante su etapa básica de crecimiento, con lo cual las exponían a una muerte segura ${ }^{29}$.

Garcilaso de la Vega, en los Comentarios reales de los incas (libro 8, cap. XVI), al describir la llama y la alpaca, afirma tajantemente: "De la leche de un ganado ni del otro se aprovechan los indios, ni para hacer queso, ni para comerla fresca; verdad es que la leche que tienen es poca más de la que han menester para criar a sus hijos"24.

Francois Gresloy afirma, por su parte, que "los pastores buscaron en los camélidos cuatro fuentes de utilidad: lana (fibra), animal de carga, estiércol (taqya) y carne. Nunca los camélidos fueron utilizados como fuente de leche para consumo humano" 39 .

En el libro de Bonavia mencionado anteriormente, se hace un recuento de los autores que rechazan el consumo de leche de llama:

- Tschudi (1885): “...aunque la llama tiene ubres con cuatro pezones y da leche en abundancia, jamás ha sido ordeñada ni por los peruanos incaicos ni por sus sucesores hasta el día de hoy. La razón de esto está en el natural indómito y arisco de estos animales...”2.

- Troll (1958) dice que "la leche no es utilizada, y no desarrollaron este uso porque afirman que debe ser destinada a las crías y porque los pezones no son tan grandes como para poder ordeñar" ${ }^{32}$. 
- Gade (1985), afirma que la razón fundamental por la que no se utilizó la leche es porque “...simplemente no fue un patrón cultural andino"2.

- Wheeler (1985), al afirmar que nunca se utilizó la leche de camélidos, reconoce que lo hace "...sin que conozcamos bien la razón de este desdén”2.

En visitas realizadas a mercados del Cusco, como los mercados Santa Clara y el mercado Wanchaq, se consultó en los puestos de venta que se dedican a productos destinados a la hechicería, pagos a la tierra, etc., si vendían o utilizaban leche de llama en cualquiera de sus formas, las respuestas fueron tajantemente negativas y hasta indignadas.

\section{MATERIAL Y MÉTODO}

El método utilizado es del tipo no experimental histórico, y se tomaron como referentes a los pobladores sudamericanos, las llamas y su manejo, así como la probable utilización de su leche.

Los eventos o procesos investigados fueron: a) el desarrollo del hombre sudamericano en relación con la crianza de la llama, y b) el uso de productos obtenidos de esta, particularmente el probable uso de su leche. Se tuvo como objetivo principal determinar el probable uso de la leche de llama, en cualquiera de sus formas y por cualquier motivo.

\section{Fuentes de información}

Se utilizaron informaciones obtenidas de fuentes confiables, como son los libros de cronistas, científicos e historiadores reconocidos. Asimismo se recogieron los testimonios de profesionales dedicados a la investigación de los ca- mélidos sudamericanos. También se han tomado informaciones de Internet, siempre que hayan especificado sus fuentes. La búsqueda bibliográfica y documentaria se realizó principalmente en:

- Biblioteca Nacional.

- Antigua Biblioteca del Instituto Peruano de Medicina Tropical (INMETRA), hoy Instituto Nacional de Salud (INS).

- Biblioteca del Instituto de Estudios Peruanos.

- Biblioteca de la Universidad Nacional Agraria.

- Bibliotecas particulares.

Asimismo, se realizaron entrevistas con profesionales dedicados a la investigación de los camélidos sudamericanos así como a las fuentes alimentarias del Perú. Estos profesionales pertenecen fundamentalmente a las siguientes instituciones:

- Consejo Nacional de Camélidos Sudamericanos (CONACS).

- Instituto Veterinario de Investigaciones Tropicales y de Altura (IVITA).

- Instituto Nacional de Investigaciones Agropecuarias (INIA)

- Universidad Nacional del Altiplano (Puno).

- Universidad Nacional San Antonio Abad del Cusco.

- Universidad Alas Peruanas (UAP).

\section{DISCUSIÓN}

Con todo lo expuesto, es innegable que la llama es quizás el animal nativo más valioso que posee el Perú, ya que provee alimentos y materia prima abundante, todos ellos de primera calidad. Así también, podemos definir a la llama y al resto de camélidos como animales "ecológicos", ya que no dañan el suelo por donde caminan ni arrancan el pasto que comen sino que lo cortan, permitiendo un rebrote más rápido.

Centrando la discusión en el punto de inte- 
rés, que es la leche de llama y su consumo por el hombre sudamericano, se analizará cada uno de los puntos encontrados, tanto a favor como en contra, en lo referente a su explotación y consumo, así como las razones esgrimidas.

Muchos autores consideran que la leche de llama o de cualquier otro camélido sudamericano no ha sido utilizada por el hombre. En el otro extremo se encuentran autores que mencionan que en Sudamérica se consumió o consume leche de llama, como los cronistas fray Vicente Valverde, fray Diego de Ocaña y Alonso Gonzales Nájera. Apreciaciones similares nos ofrece el entomólogo inglés Henry Walter Bates, el geógrafo peruano Emilio Romero y otros profesionales.

Algunas de las razones dadas para el no consumo de la leche de llama carecen de sustento científico. Nos referimos básicamente a aquellas que afirman que la leche de llama es no apta para el consumo humano por su alto contenido de grasa, lo que no es cierto, ya que posee un 3,37\% de grasa, contra un 3,68 5 de la leche de vaca, que puede llegar hasta el $6 \%$. En este mismo sentido, la propia leche de humana alcanza un promedio de grasa del $4,2 \%$, y el de la de cabra llega hasta un contenido del $4,1 \%$ de grasa.

Asimismo, el pretendido "altísimo" nivel de proteínas no es tal, ya que la leche de llama tiene un nivel proteico del 3,9\%, el cual, si bien es mayor al de otras especies, como la bovina (3,39\%) y la caprina $(3,3 \%)$, no la convierte en no apta para el consumo humano, pues la leche de oveja, que alcanza el 5,8 \%, sí es consumida. Y si tomamos como referencia el nivel proteico de la leche humana, con un nivel de $1 \%$, es claro que cualquiera de las leches anteriormente mencionadas alcanza un nivel mayor.

En relación con su alto contenido de minerales $(0,8 \%)$, entre los que se encuentra el calcio, debemos decir que este supera al de la vaca, que tiene un $0,72 \%$. Esto le da un mayor valor nutricional a la leche de llama, en lugar de restárselo. Asimismo, el contenido de minerales de la leche de llama es mayor al de la leche de cabra y de oveja, que tienen un contenido mineral de $0,85 \%$ y $0,93 \%$ respectivamente.

El sabor de la leche de llama se puede definir como agradable y de un dulzor medio, nunca desagradable, como se ha tratado de definir en algunos casos. La única forma de sentir un sabor desagradable en la leche de llama es si por error se ha tomado el calostro, el cual tiene un sabor ligeramente salado.

En referencia a la poca producción lechera de las lamas, se encontró que en promedio esta es mínima; sin embargo, se han encontrado algunos animales que producen entre 3 y 4 litros de leche al día, sin ningún tipo de selección o manejo especial. Igualmente resultan válidas las observaciones de que las ubres y los pezones de las llamas son muy pequeños y que eso dificulta su ordeño, pero no lo imposibilita.

Decir que las llamas son animales ariscos y no permiten su ordeño resulta también una afirmación atendible, pero tal situación debe ser entendida como producto de la falta de costumbre de los animales a este tipo de manejo, ya que está comprobado que las llamas son animales sumamente dóciles con sus amos y que responden bien al buen trato.

De las explicaciones de índole ideológica que se describen en el trabajo, el respeto a los animales por parte del poblador andino pudo haber sido un fuerte obstáculo para el consumo de la leche de llama, ya que ante todo el hombre andino respeta toda forma de vida, y en especial si esta trae beneficios para el hombre. En tal sentido, el manejo adecuado, dando un especial énfasis al respeto de los animales hembras como medio de propagación de la especie, es un dogma muy arraigado en la cosmovisión del hombre andino; 
incluso existía en el incanato una ley que prohibía matar o dañar a los animales hembras en edad reproductiva.

La cosmovisión andina concibe el universo como un todo, y considera a sus animales, principalmente los camélidos, como seres de igual valía e importancia que la raza humana. Esa forma de ver a los animales y su entorno desvirtúa la hipótesis del no consumo de leche de llama debido a las ideas matriarcales de mutilación a su capacidad maternal vinculadas a tal consumo.

Una razón de peso para el no consumo de la leche de llama es aquella que sostiene la no necesidad de tal consumo, toda vez que los bebés lactaban normalmente hasta los 2 años de edad, con lo que se aseguraba la cantidad de nutrientes en la primera etapa del desarrollo humano. Además, se sabe que la alimentación andina fue quizás una de las más completas y balanceadas que hayan existido, puesto que consumían gran variedad de vegetales, tubérculos, peces, carnes, cereales y suplementos minerales que cubrían con creces las necesidades del hombre andino.

Podría sostenerse que en la alimentación andina existía un déficit de calcio, pero se sabe también que muchos productos de origen vegetal, como la quinua, la coca, etc., poseen considerables cantidades de este mineral, que a su vez era consumido en forma de cal acompañando a muchos alimentos, sopas o lawas o cancha, por ejemplo. El calcio está contenido en gran variedad de alimentos consumidos por el antiguo poblador andino, los mismos que, acompañados por la chicha, preparada en diversos volúmenes alcohólicos, cubrían con creces los requerimientos de calcio del organismo.

Buscando indicios de la existencia de un consumo de leche de llama, se encuentran afirmaciones positivas de autores que merecen ser considerados, como son fray Vicente de Valverde, fray Diego de Ocaña y Alonso Gonzales de
Nájera. En tal sentido, sus afirmaciones podrían ofrecer pistas reales sobre el consumo de la leche de llama, pues estos personajes conocieron los territorios del imperio desde el inicio de la conquista, aunque es bien sabido que el proceso de transculturación fue vertiginoso, provocando que estos cronistas hubieran simplemente observado a los primeros pobladores postconquista practicando el ordeño de llamas por imitación.

Afirmaciones como las de Henry Walter Bates, el geógrafo peruano Emilio Romero y otros profesionales como Ramón Solís, Ordóñez o Eliseo Fernández Ruelas podrían sugerir una utilización reciente de la leche de llama, aunque de forma restringida y ligada al ámbito de la subsistencia o para cubrir la falta de leche de otras especies animales, caso este en que se consume combinada.

\section{CONCLUSIONES}

$\mathrm{Al}$ analizar los datos obtenidos en el transcurso de la presente investigación, se llegó a las siguientes conclusiones:

- Las conclusiones pueden no ser definitivas, de encontrarse nuevas fuentes de información que sustenten lo contrario.

- No se mencionan otros períodos históricos anteriores al incanato, ya que no se encontró evidencia alguna sobre un posible consumo de la leche de llama.

- La leche de llama en Sudamérica no fue utilizada por los pobladores andinos durante el incanato porque contaban con otras fuentes de calcio y minerales, y por una cuestión de respeto a los animales y a sus crías.

- Se pudo dar un consumo restringido luego de la conquista, como parte del proceso de transculturación -en este caso por imitación-, pero finalmente este nuevo hábito se fue perdiendo, hasta el punto que hoy solo se practicaría por razones de subsistencia. 


\section{RECOMENDACIONES}

- Continuar con una línea de investigación destinada al mejoramiento de las llamas como animales lecheros y proveedores de otros productos, realizando inicialmente un estudio de las perspectivas que tales productos ofrecen.

- Realizar estudios que reafirmen el nivel productivo de estos animales (curva de lactación).

- Realizar estudios sobre la factibilidad de fabricación de diversos productos, como queso, yogurt, etc.

- Realizar mayores estudios de las características químicas y organolépticas de la leche de llama, para estandarizar los datos y determinar si estos varían según el clima y la alimentación.

\section{REFERENCIAS BIBLIOGRÁFICAS}

1. Brack A. Econegocios. Cría de la llama. Agosto de 2003. Disponible en:

http://www.peruecologico.com.peleconeg_llama.htm

2. Bonavia D. Los camélidos sudamericanos (una introducción a su estudio). Lima, IFEA - UPCH- CI, 1966: 51, 77, 500-501, 560.

3. Sumar J. "Los camélidos domésticos en el Perú". Boletín de Lima. Enero de 1992, No 79: $81-95$.

4. Mogrovejo D. Boletín: Crianza de la llama.

5. Gispert C. "Auquénidos, producción ganadera". En: Biblioteca práctica agrícola y ganadera. España, Editorial Océano, 1984; 4:93.

6. Anónimo. "Suborden de los tilópodos, familia de los camélidos". Enciclopedia de los animales. España, editorial Abril, Noguer,
Rizoli, Larousse, 1971; 56:289, 296, 305, 306.

7. Cardich A. "Origen del hombre y de la cultura andina”. En: Historia del Perú. Sexta edición. Lima, Juan Mejía Baca editor, 1985; 1:31-156.

8. Matos M., Rabines R. "El período arcaico". En: Historia del Perú. Sexta edición. Lima, Juan Mejía Baca editor, 1985; 1: 196-197.

9. Rostworowski M. "Los recursos renovables del Tahuantinsuyu, la ganadería”. En: Historia del Tabuantinsuyu. Tercera edición. Lima, IEP, 1988: 251-257.

10. Randal R. "Crianza de llamas y alpacas". En: Proyecto Alpacas PAL. Lima, Convenio COTESU - INIA, 1989: 19-20.

11. "Crianza de llamas y alpacas". En: Proyecto Alpacas PAL. Lima, Convenio COTESU INIA, 1989: 20, 21, 22, 23, 24, 87.

12. Flores Ochoa J. "Crianza de llamas y alpacas". En: Proyecto Alpacas PAL. Lima, Convenio COTESU - INIA, 1989: 20, 21, 22, 24.

13. Kent J. "Crianza de llamas y alpacas". En: Proyecto Alpacas PAL. Lima, Convenio COTESU - INIA, 1989: 25.

14. Buztinza J. “Crianza de llamas y alpacas”. En: Proyecto Alpacas PAL. Lima, Convenio COTESU - INIA, 1989: 95.

15. FAO. De dromedarios y llamas. Enfoques. Sep 2001. Disponible en: bttp://www.fao. org/WAICENT/FAOINFO/AGRICULT/ esp/revista/0108sp.htm

16. Leguía G. Enfermedades parasitarias y Atlas parasitológico de camélidos sudamericanos. Lima, Editorial De Mar, 1995: 5.

17. Mora J. Opciones de ganadería en sistemas de producción campesinos de América Latina. Febrero de 2002. Disponible en: bttp:// lead.virtualcentre.org/es/enl/keynote3.htm

18. Solís R. Producción de camélidos sudamericanos. Huancayo, 2000: 413-434. 
19. Fowler E. Medicine and Surgery of South American Camelids: Lama, Alpaca, Vicuna, Guanaco. Segunda edición. Iowa State University Press, 1998.

20. Tibary A., Anouassi A. Lactation and Udder Diseases. Department of Veterinary Clinical Sciences, College of Veterinary Medicine. Washington State University, Pullman, Washington, USA. Agosto de 2003. Disponible en: bttp://www.ivis.org/advances/Camed Skidmore/tibary4/chapter frm.asp?L $A=1$

21. Anónimo. Camélidos andinos, Qosqo. Junio de 2002. Disponible en: http://users.bestweb. net/ goyzueta/qosqoes/camelidos.html

22. Raggi L. Características fisiológicas y productivas de los camélidos sudamericanos domésticos. Ovulación. Facultad de Ciencias Veterinarias y Pecuarias de la Universidad de Chile. Julio de 2003. Disponible en: http://mazinger.sisib.uchile.cl/repositorio/lb/ciencias_veterinarias_y_pecuarias/simposio 1993/ 06areafaunaalti/40 a html\#26v

23. Raggi L. Los camélidos sudamericanos domésticos, llama y alpaca. Facultad de Ciencias Veterinarias. Agosto de 2003. Disponible en: http://www.cev.cl/secciones/articulos/ llamas\%20y\%20alpacas.htm

24. Inca Garcilaso de la Vega. Comentarios reales de los incas. Tomo 2, capítulo X. "El orden y división del ganado y de los animales extraños". Lima, Editorial Inca S.A. (PEISA), 1973: 70.

25. CIRAD. Centre de coopèration internationale en recherche agronomique pour le développement. Cámelides. Genre lama. Julio 2003. Disponible en: http://camelides.cirad. fr/fr/curieux/lama.html

26. Morin E., Hurley L. Composition of Milk from llamas in the United States of America. Pub Med USA: ed J Dairy Sci 1995; 78: 1713-1720.

27. Microsoft. "Camélidos sudamericanos". En:
Enciclopedia Microsoft Encarta 2000, España, 2000.

28. Flores Ochoa J. Pastores de alpacas. Abril de 2003. Disponible en: http://www.agualtiplano.net/pueblos/ejes5a.btm

29. Antúnez de Mayolo S. La nutrición en el Antiguo Perú. Lima, BCR, Numismática Ediciones, 1981: 57, 87, 134 .

30. Espinoza W. "Ayllu, familia, tierra y otros aspectos de la vida cotidiana. Alimentación". En: Los incas, economía, sociedad y estado en la era del Tahuantinsuyo. Lima, Editorial Amaru, 1990: 143-144.

31. Ordóñez T. Llamas, Llama Production and Llama Nutrition in the Ecuador Highlands. Arid Environ, 1994; 26: 67-71.

32. Fernández E. "Aporte de la llama a la economía campesina”. En: V Congreso Internacional de Sistemas Agropecuarios Andinos, Puno, Perú, 10-14 de mayo de 1986. Lima, Editorial Adolfo Arteta, 1987: 416

33. Moro M. "Contribución al estudio de la leche de las alpacas". Revista de la Facultad de Medicina Veterinaria de la UNMSM. Vol. VII-IX. Barranco, Perú, 1952-1956: 122.

34. Leyva V. Director de IVITA. Agosto de 2002. Lima, Perú.

35. Mora-Delgado J., Holguín V. Ganadería en sistemas de producción campesinos en América Latina. Editorial Boletín Electrónico del LEAD. VOL “, No 1. Febrero de 2002. Disponible en: http://lead.virtualcentre.org/ es/enl/keynote3.htm

36. Antúnez de Mayolo S. "Genética”. Boletín. Lima, BCRP, 1999: 19.

37. Horkheiner H. Alimentos del Perú. Historia. Época prehispánica. Lima, 1973: 61-62.

38. Cabieses F. Cien siglos de pan: 10000 años de alimentación en el Perú. Segunda edición, Lima, Univ. San Martín de Porres, 1990: 3435. 
39. Gresloy F. Crianza de llamas y alpacas. En: Proyecto Alpacas PAL. Lima, Convenio COTESU - INIA, 1989: 17.

40. Enciclopedia Británica. "Leche e industria de la leche". En: Enciclopedia BARSA. USA, Editorial William Benton, 1965; 9: 304.

41. Vendedores del Mercado Santa Clara y Wanchaq del Cusco. Abril de 2004, Cusco, Perú.

42. Rodríguez J. Los chibchas: pobladores antiguos de los andes orientales. Aspectos bioantropológicos. Pseudocereales. Universidad Nacional de Colombia. Enero de 2004. Disponible en: http://www.colciencias.gov. co/seiaal/documentos/jurc04c4c2.htm

43. The Contracting Society. Articulación de mercados,quinua. Febrero de 2004. Disponible en: http://www.contractingsociety.com/ mercados.htm

44. Marchese P. Las comidas andinas. La quinua, la quiwicha, el tarwi, el chuño. Febrero de 2004. Disponible en: http://www.pas- qualinonet.com.ar/la_comida_andina.htm

45. Anónimo. La mama coca, algo más que alimento andino. Mayo de 2004. Disponible en: bttp://elmarboliviano.blogspot.com/2004_ 04_05_elmarboliviano_archive.html

46. Wheeler J. Producción de camélidos. Marzo de 2004. Disponible en: http://www.puc.cl/ sw_educ/prodanim/notrad/siv4.htm

47. Vizcardo N. Profesora de quechua de la UAP. Comunicación personal. Marzo de 2004, Lima, Perú.

48. Guardia C. Diccionario Kechwa-Español. /ma. Edición. Lima, Editorial Minerva, 1997: 213.

49. Callasaya H. Consejo Nacional de la Cultura y las Artes de Chile. Programa "Ser indígena”. Diccionario Aymara-Español. Octubre de 2003. Disponible en: http://www.serindigena.cl/territorios/recursos/biblioteca/ diccionarios/ayma_espa/s.htm 